\title{
Thank You to a Class Act
}

\author{
Suzanne F. Bradley, MD
}

Whatever happened to class? (Chicago the Musical, Fred Ebb, lyricist, and John Kander, composer)

In 2006, Dr. Jarvis described Infection Control and Hospital Epidemiology $(\mathrm{ICHE})$ as a journal transitioning through adolescence with the assistance of a new publisher, the University of Chicago Press (UCP). ${ }^{1}$ Major issues of that day included a large backlog that occurred as a consequence of rising submissions and stable rejection rates. Since that time, the journal has continued to thrive; we anticipate that in 2014 the number of submissions will have almost doubled over the past 8 years. Five supplements have been published during this time frame, and three of these issues were released just in the last 5 months.

Founded as one of the main divisions of the University of Chicago, UCP has clearly met its overarching academic mission to "disseminate scholarship of the highest standard." ICHE is an outstanding example of that commitment. No matter how busy ICHE has become, UCP has never thought twice about increasing resources and staff to get the job done. We thank the current and former directors of the UCP Journals Division, Michael Magoulias and Everett Conner, and the publisher, Gordon Rudy, for their unwavering support of ICHE. The managing editor is typically the public face of ICHE and the first person that authors, readers, editors, and society members encounter when seeking advice about matters pertaining to the journal. Rob Blixt and his predecessors, Gordon Rudy and Anne Marie McCormack, have served as outstanding resources for publishing advice and customer service while simultaneously maintaining the flow of papers from the editorial office to production, a major feat in itself. Finally, there are many people who have worked in relative anonymity to make sure that accepted papers are meticulously and accurately copy edited and typeset. There have been very, very few errata on UCP's watch.

Over the past few years, the economic downturn has greatly affected academic and for-profit publishers alike, resulting in increasing competition for fewer subscribers (libraries, healthcare facilities, and individuals) and declining advertising dollars. In 2013, the Society for Healthcare Epidemiology of America board of directors elected to hire a new publisher, Cambridge University Press, effective January 1, 2015. During this time of transition, UCP has worked very closely with Cambridge staff to assure that the journal's processes, submissions, and archived materials are transferred seamlessly. I am confident that you will not notice any changes in the functioning or quality of ICHE in the days to come.

In their lyrics, Ebb and Kander bemoaned the lack of values, manners, and mores among the citizens of the Windy City during the early twentieth century. In fact, be assured that "class" is alive and well and residing within the walls of UCP.

\section{RE F E REN C E}

1. Jarvis WR. Infection Control and Hospital Epidemiology: transitioning through adolescence! Infect Control Hosp Epidemiol 2006; 27:1-2. 